\section{Dating sea level in caves}

SIR - In their account of their dating of the calcite deposits (known as speleothem) from a cave in the Bahamas, Li et al. ${ }^{1}$, refer in Table $1 b$ to "equivalent samples" of the DWBAH speleothem. But inspection of Fig. 1 shows that some of the samples compared are not stratigraphically equivalent. For example, alphacount-dated sample MB is coupled with mass-spectrometrically dated sample A1 in the table; yet, as is clear from Fig. 1, sample $\mathrm{MB}$ is at least twice as thick and contains younger material than sample A1. No wonder that it dates $\sim 40$ kyr younger than A1. Similarly, alpha-dated sample TT, which is coupled with massspectrometrically dated sample 18 , contains flowstone stratigraphically older than in sample 18; and not surprisingly has a much older date. Where the massspectrometrically dated sample is from a stratigraphic interval near the middle of the thicker alpha-dated samples, comparable ages are obtained in two of three cases. The authors point out (Fig. 1 legend) that about ten times as much sample is needed for alpha-count as for mass-spectrometric dating. Nevertheless, a meaningful comparison of the alphacount and mass-spectrometric ages requires samples from identical stratigraphic levels, a procedure not followed.

Li et al.' claim (their Fig. 3) that sea level was below about $-12 \mathrm{~m}$ (the depth of speleothem DWBAH) between 135 and $215 \mathrm{kyr}$ before present (BP), and that their record is generally "in agreement with the high-sea-stand chronology inferred from oxygen isotope stratigraphy of oceanic foraminiferal cores". Unfortunately, they fail to cite published evidence to the contrary. R. S. Harmon et al. ${ }^{2}$ have used $\alpha$-counting dates of submerged speleothem and emerged corals to show that sea level stood between the modern level and -6 m about 195-210 kyr ago. Moreover, the high stand shown in ref. 2 falls beneath the highest $\delta^{18} \mathrm{O}$ peak of marine isotope stage 7 reproduced by Li et al. (their Fig. 3 ) at a time when they indicate sea level as below $-12 \mathrm{~m}$. Figure 6 of ref. 2 also shows a short-lived sea-level high (shallower than $-7 \mathrm{~m}$ ) at about $145-150 \mathrm{kyr}$ BP, when Li et al. indicate that sea level stood below $-12 \mathrm{~m}$, and possibly ${ }^{3}$ deeper than $-40 \mathrm{~m}$.

That sea level may have reached or exceeded modern levels by $145 \mathrm{kyr} \mathrm{BP}$, in contradiction to the marine $\delta^{18} \mathrm{O}$ chronology and to the data of ref. 1 , is supported by other studies from the Bahamas, and from adjacent southern Florida. Alphacount dating of corals and ooids from the Bahamas indicates that the sea-level history of this relatively stable platform is complex, with one or more high sea-level stands between 100 and $145 \mathrm{kyr} \mathrm{BP}^{+.5}$. For example, Neumann and Moore dated two
Bahamian corals at $146 \pm 9 \mathrm{kyr}$ BP and 140 \pm 9 kyr BP; these corals were $>95$ per cent aragonite. And the Key Largo Limestone of south Florida was dated at 139 $(+19 /-14)$ kyr BP (an average taken from the data of 13 participating laboratories) resolution obtainable by mass spectrometry in a time range where the resolution of alpha-count dates is poor (below Hiatus 1) and in pinpointing events (terminations). The alpha-count dates in question have high error because of low uranium contents ( 0.09 p.p.m. on average) and low yields (32-80\% for $U$, and $8-65 \%$ for $T h$ ).

Winograd also questions the number

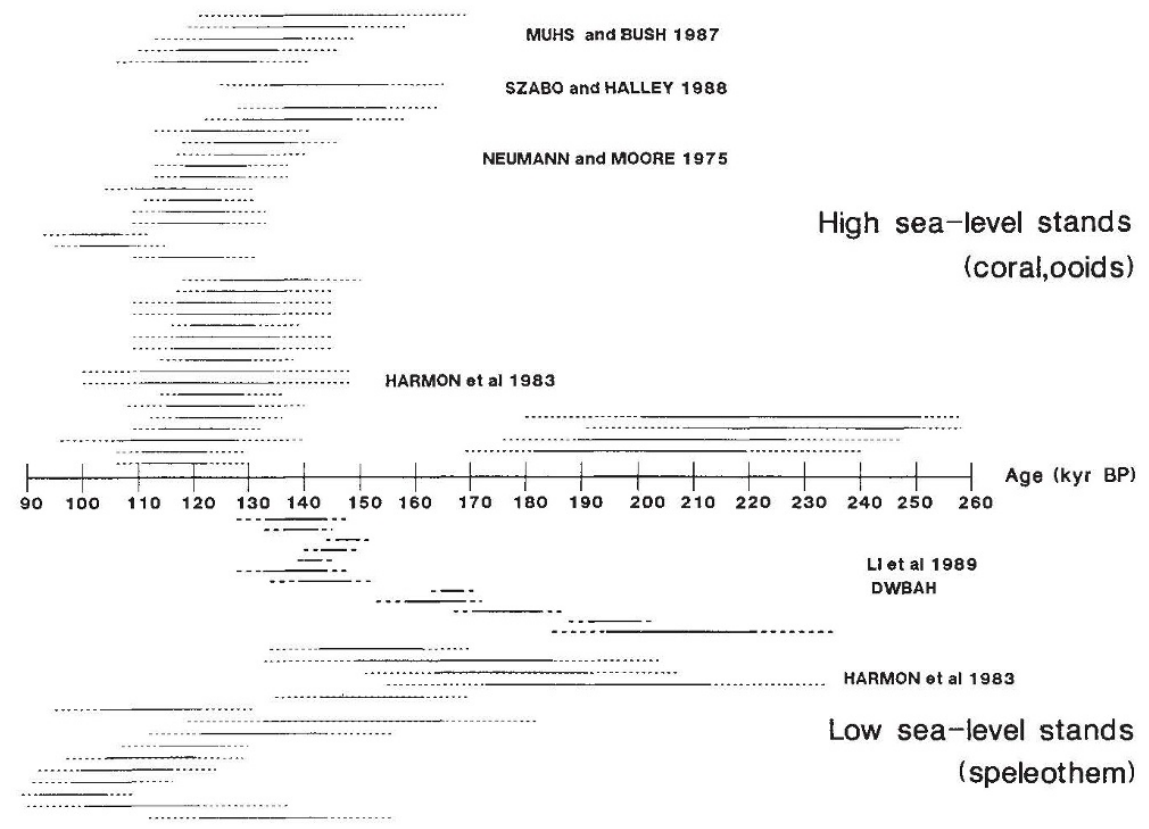

Dates on corals and ooids indicate high sea-level stands; those on drowned speleothem indicate low sea-level stands. $\longrightarrow$, l $\sigma$ error;,$------ 2 \sigma$ error.

during the first uranium-series intercomparison project ${ }^{6}$; the coral specimen used was 90 per cent aragonite. Recently, Szabo and Halley ${ }^{7}$ obtained an age of 145 $\pm 10 \mathrm{kyr}$ for the Key Largo Limestone using a coral containing $>97$ per cent aragonite.

Are we to assume that the dates in refs 2 and $4-7$, indicating a high sea-level stand at around 140-150 kyr BP, are all 10-20 kyr too old? Or might there be an undetected hiatus in speleothem DWBAH between 145 and 165 kyr BP? No ages are provided by $\mathrm{Li}$ et al. ' for this time interval, which corresponds to a $15 \mathrm{~mm}$ thickness of DWBAH (their Fig. 2). No other interval this thick is undated in DWBAH.

Speleothem DWBAH provides the authors with an excellent opportunity to address explicitly the decade-old debate of whether the last interglacial was marked by a single or a double rise in sea level, I urge them, therefore, to address these matters.

ISAAC J. WINOGRAD

US Geological Survey,

National Center (432),

Reston, Virginia 22092, USA

LUNDBERG ET AL. REPLY-Winograd is right in saying that the alpha-count and mass spectrometric dates in Table $1 b$ are not directly comparable. They were not intended to be; they show the superior and ages of high sea-level stands during isotope stages 7 and $5 \mathrm{e}$. Although it is customary to quote $\alpha$-counting dates with only $1 \sigma$ error (the $68 \%$ confidence interval), there is a $32 \%$ probability that the true value is not in this range. If one looks instead at the $2 \sigma$ errors ( $95 \%$ confidence interval), many apparent conflicts with the mass-spectrometry data disappear (see figure).

Harmon et $a .^{2}$ suggest that sea level rose to about $+2 \mathrm{~m}$ between 210 and 190 kyr BP. In our DWBAH sample the first mass-spectrometric date after the stage $7 \mathrm{a} / 7 \mathrm{c}$ recession (sample $\mathrm{A} 1$ ) is $237-186 \mathrm{kyr}$ $\mathrm{BP}$ ( $2 \sigma$ range). The equivalent stalagmite date in ref. 2 is $235-155 \mathrm{kyr}$ ( $2 \sigma$ range). Their four coral dates for the previous high sea-level stand range from 282 to 168 kyr; their coral and stalagmite dates overlap each other and both of the stage 7 hiatuses ( 1 and 2 ) resolved by mass spectrometry. Note that the date of isotope stage $7 \mathrm{a}$ itself has been only approximated (by orbital tuning), and that Chappell and Shackleton ${ }^{8}$ modified their sea-level curve to fit this expected rise: their original (pre-tuned) dates at $\sim 220$ and $235 \mathrm{kyr}$ BP coincide with hiatuses 2 and 1 (at around 220-212 and 235-230 kyr BP) from DWBAH.

The marine isotope record gives no reason to suspect a rise of sea level to modern heights at $\sim 145 \mathrm{kyr} \mathrm{BP}$, although 